\title{
Psychogenic non-epileptic seizures (PNES) in the context of concurrent epilepsy - making the right diagnosis
}

\author{
Andreas Liampas ${ }^{1 *}$ (1), Sofia Markoula ${ }^{2}$, Panagiotis $Z_{i s}^{1,3}$ and Markus Reuber ${ }^{4}$
}

\begin{abstract}
Epilepsy is a risk factor for the development of psychogenic non-epileptic seizures (PNES) and comorbid epilepsy is recognized as a comorbidity in about $10-30 \%$ of patients with PNES. The combination of epileptic and nonepileptic seizures poses a particular diagnostic challenge. In patients with epilepsy, additional PNES may be suspected on the basis of their typical semiology. The possibility of additional PNES should also be considered if seizures fail to respond to antiepileptic drug treatment, in patients with frequent emergency admissions with seizures and in those who develop new types of seizures. The description of semiological details by patients and witnesses can suggest additional PNES. Home video recordings can support an initial diagnosis, however, especially in patients with mixed seizure disorders it is advisable to seek further diagnostic confirmation by capturing all habitual seizure types with video-EEG. The clinical features of PNES associated with epilepsy are similar to those in isolated PNES disorders and include longer duration, fluctuating course, asynchronous movements, pelvic thrusting, side-to-side head or body movement, persistently closed eyes and mouth, ictal crying, recall of ictal experiences and absence of postictal confusion. PNES can also present as syncope-like episodes with unresponsiveness and reduced muscle tone. There is no unique epileptological or brain pathology profile putting patients with epilepsy at risk of additional PNES. However, patients with epilepsy and PNES typically have lower educational achievements and higher levels of psychiatric comorbidities than patients with epilepsy alone. Psychological trauma, including sexual abuse, appears to be a less relevant aetiological factor in patients with mixed seizure disorders than those with isolated PNES, and the gender imbalance (i.e. the greater prevalence in women) is less marked in patients with PNES and additional epilepsy than those with PNES alone. PNES sometimes develop after epilepsy surgery. A diagnosis of'known epilepsy'should never be accepted without (at least brief) critical review. This narrative review summarises clinical, electrophysiological and historical features that can help identify patients with epilepsy and additional PNES.
\end{abstract}

Keywords: PNES, Epilepsy, Risk factors, Diagnosis

${ }^{*}$ Correspondence: liampasand@gmail.com

1 Department of Neurology, Nicosia New General Hospital, Nicosia, Cyprus

Full list of author information is available at the end of the article

\section{Background}

Psychogenic non-epileptic seizures (PNES) are experiential and behavioral responses to adverse internal and external stimuli involving loss of self-control and arousal. They are typically perceived as involuntary and resemble epileptic seizures or can be misdiagnosed as such. In contrast to epileptic seizures, which are a manifestation of excessive and hypersynchronous discharges in the brain, PNES are not associated with original author(s) and the source, provide a link to the Creative Commons licence, and indicate if changes were made. The images or other third party material in this article are included in the article's Creative Commons licence, unless indicated otherwise in a credit line to the material. If material is not included in the article's Creative Commons licence and your intended use is not permitted by statutory regulation or exceeds the permitted use, you will need to obtain permission directly from the copyright holder. To view a copy of this licence, visit http://creativecommons.org/licenses/by/4.0/. 
epileptic electroencephalographic (EEG) abnormalities or any other identifiable pathophysiological changes [1, 2].

The incidence of PNES in the general population is about 4.9/100,000 cases per year [3]. However, this may be an underestimate, because it is based on video-EEG proven diagnoses. PNES are more frequent in patients with epilepsy. A recent systematic review and metaanalysis of a large number of cohort studies reported that a mean of $22 \%$ of patients with PNES have additional epilepsy and a mean of $12 \%$ of patients in cohorts with a primary diagnosis of epilepsy have comorbid PNES [4]. These prevalence rates of mixed seizure disorders may be overestimates because many of the studies included in the meta-analysis used relatively broad definitions of epilepsy and PNES. Mixed seizure disorders are identified less commonly when more stringent diagostic criteria are applied-such as video-EEG documentation of both seizure types [5]. These percentages may also be overestimates because the majority of studies were from tertiary epilepsy centers where more complex cases would typically be referred. However, almost all cohort studies report a higher epilepsy prevalence among patients with PNES (and a higher prevalence of PNES among those with epilepsy) than reported for the general population [4]. In patients with a dual diagnosis, epilepsy almost always presents first. Hence, epilepsy may be considerd as a risk factor for PNES development [6-9]

Despite many well-described features of differential diagnostic value, PNES can still be difficult to diagnose. This challenge is particularly great when epilepsy and PNES coexist in the same patient and when each further seizure which occurs after the initial diagnosis requires careful assessment to ensure that the correct treatment choices are made.

Patients with epilepsy and PNES may suffer from more adverse side effects than patients with epilepsy since they often receive polytherapy with several antiseizure medicines (ASMs) in higher dosages [10]. Furthermore, when these patients present with PNES- 'status', intravenous anticonvulsants and the induction of general anaesthesia may produce iatrogenic complications, and even cause death. [11]. Hence, the early recognition of PNES in individuals who have previously been diagnosed with epilepsy is of great importance for safe medical management [12].

In this narrative review we initially summarize demographic, etiological and clinical features of patients with PNES and comorbid or pre-existing epilepsy before focusing on the diagnostic methods available to clinicians to help with the recognition of comorbid PNES disorders among their patients with epilepsy.

\section{Demographic features of patients with PNES and epilepsy}

There are many uncertainties about the demography of patients who suffer from both PNES and epilepsy, and about the question whether the demographic characteristics of the group of patients with PNES and epilepsy differ from those of patients with PNES alone. One important reason for this is that there are no community-level studies specifically focusing on patients with mixed seizure disorders. Studies based at epilepsy centers are likely to be affected by selection bias. In their meta-analysis of patients with mixed seizure disorders, Kutlubaev et al. concluded that there are no differences in the demographics between patients with epilepsy and concurrent PNES and those with PNES alone [4]. Among patients with PNES but no epilepsy, PNES mostly manifest in the mid-teens to mid-twenties, although they have been described in children as young as five and there is no upper age limit [13]. There is conflicting evidence about the effect of the age of onset of epilepsy on the risk of subsequent PNES development. A later onset of epileptic seizures has been proposed as a predisposing factor for PNES development [14, 15], but this was not confirmed in two other studies $[5,8]$.

A female preponderance has been documented in many studies of unselected populations with PNES [8, 16] or other somatoform disorders [17]. In a systematic review, Baroni et al. also showed a clear female predominance in populations with concurrent PNES and epilepsy [18]. However, a female predominance has not been documented in some subpopulations in whom PNES are particularly likely to be associated with epilepsy, e.g. in pediatric populations, intellectual disability (ID) cohorts or the elderly [19-21]. The prevalence of PNES (without comorbid epilepsy) is higher among socially disadvantaged populations [22]. Recent research suggests that patients with PNES alone and patients with PNES and epilepsy are at a similarly increased risk of premature death as patients with epilepsy [23]. The cause of the excess mortality associated with PNES (alone or combined with epilepsy) is not fully understood.

\section{Etiology of PNES in patients with additional epilepsy}

PNES is a heterogeneous disorder, associated with a variety of other mental health problems and disorders [2]. In the traditional conversion and dissociation models of PNES, specific stressors precipitating PNES disorders and triggering individual seizures become pathogenic through their interaction with a variety of predisposing/ environmental factors, especially traumas and dilemmas [24]. In such accounts of PNES, epilepsy may predispose, precipitate, perpetuate or trigger PNES [6-9]: The contribution of epilepsy to the development of PNES may be 
more direct [25], as shown by Devinsky and Gordon who reported that PNES may be triggered by focal seizures without consciousness impairment [26] or more indirect, via epileptic seizure-related physiological arousal or through epilepsy-associated comorbid psychosocial problems such as anxiety disorders, social isolation, shame or stigma [4].

Brown and Reuber proposed an Integrative Cognitive Model of PNES incorporating previous theories about PNES in order to provide a more specific account of how PNES may be triggered in the brain. They suggested that PNES constitute one particularly prominent temporary peak of abnormal brain functioning with more subtle abnormalities of functioning being evident during the interictal period. They hypothesised that the preconscious activation of rogue mental representation (the 'seizure scaffold') by internal or external triggers is a feature which may characterize all PNES (with the exception of superficially similar events resulting from patients' willed action, e.g. in the context of malingering or factitious disorder) [27]. These rogue representations consist of cognitive-emotional-perceptual-behavioral programs that combine elements of inherent schemata (such as how to respond to fear) with the results of learning and experience across multiple contexts. Activation of the scaffold may be associated with abnormal arousal, emotion or cognitive processing [27]. Epilepsy fits into the ICM in different ways: epileptic seizure experiences may contribute to the seizure scaffold, represent a trigger for a threat response or be a cause of chronic stress and persistent physiological arousal diminishing the effectiveness of inhibitory mechanisms.

\section{Trauma}

Many (if not most) patients with PNES alone have a history of serious trauma or neglect. Post-traumatic stress disorder (PTSD) is a common comorbidity of PNES [28]. Several studies suggest that a history of trauma (including sexual abuse) is less often identified as a potential etiological factor in patients with a concurrent diagnosis of PNES and epilepsy than in those being diagnosed only with PNES, especially in populations in which PNES arise in the context of ID and epilepsy [20,29].

\section{Mood disorders}

Psychopathologies associated with epilepsy (including anxiety and depression) may facilitate PNES indirectly, especially by causing chronic stress and by reducing a patient's ability to inhibit the activation of the PNES scaffold [30]. In patients with epilepsy, depressive or psychotic symptoms may be associated with the pathology underpinning the seizure disorder but also the use of ASMs [31, 32].

\section{Educational level and neuropsychological impairments}

One study comparing similarly investigated groups of patients with epilepsy alone and patients with mixed epileptic/nonepileptic seizure disorder found that patients with mixed seizure disorder were more likely to have a low intelligence quotient (IQ) and neuropsychological deficits than those with epilepsy alone [8]. Yon et al. reported a lower educational status in patients with comorbid PNES and epilepsy than those with PNES alone [5]. ID per se, the stigma and discrimination associated with this or institutional care settings may be additional risk factors [19, 33-35].

\section{Treatment with antiseizure medicines}

Excessive or inappropriate use of ASMs and their adverse effects may lead to PNES in patients with epilepsy [5, $31,32,36]$. There is also some evidence that ASMs can worsen dissociative states acutely and prolong PNES 'status' [11]. In addition, some ASMs are associated with an increased risk of psychomorbidity (especially depression) which could contribute to PNES [32]. Clinical experience suggests that, in certain circumstances, ASMs may also have therapeutic effects in patients with epilepsy and additional PNES: they may improve patients' wellbeing and reduce the PNES risk by stopping epileptic seizures or through positive psychotropic effects (drugs such as lamotrigine or pregabalin may, for instance, alleviate anxiety or depression, carbamazepine may reduce aggression, a wide range of ASMs could have mood-stabilizing properties) [32].

\section{Structural pathologies}

Preexisting brain disorders which may also cause epilepsy [27] may facilitate the development of PNES. Structural brain abnormalities [5, 14, 37] and brain surgery [5] have been proposed to act as risk factors for PNES in people with epilepsy, although no clear pattern of abnormalities (e.g. in terms of lateralization or localization) has emerged [8]. Brain magnetic resonance imaging (MRI) abnormalities have been reported more frequently in patients with comorbid PNES and epilepsy than in those with epilepsy alone [5]. However, in view of the lack of persistent patterns across primary research studies, it is questionable, whether there is a direct etiological contribution from structural brain abnormalities or whether a potential increase of the probability to develop PNES is mediated through epilepsy itself, its treatment or effects on patients' lives.

\section{Epilepsy surgery}

PNES have been reported to develop for the first time after 1.8 to $8.8 \%$ epilepsy surgical procedures [14, 38-44]. 
Postoperative PNES are likely to be underdiagnosed and cause uncertainty in the determination of postsurgical epileptic seizure outcomes and in clinical management. [45]. Female patients with preoperative psychiatric disorders have been shown to be at greatest risk of postoperative PNES [44]. PNES following epilepsy surgery seem to be unrelated to postsurgical seizure outcome [44]. It has been postulated that some patients may develop PNES in the context of experiencing postoperative freedom from epileptic seizures and while struggling with a 'burden of normality' [46]. PNES may develop within 12 months of epilepsy surgery $[37,47]$, although they may also emerge several years later [44]. In patients in whom seizures keep occurring or re-emerge after completion of epilepsy surgery, the possibility of postsurgical PNES should always be considered. Especially atypical seizures not resembling the patient's previous habitual epileptic seizures [41], and those with motor manifestations [44] should be considered as 'red flags' for PNES.

\section{Clinical features}

Little is known about differences in the semiology of PNES between patients with PNES alone and those with mixed seizure disorders. Hubsch et al. identified five clusters of PNES manifestations: 1) paroxysmal dystonic episodes with primitive gestural manifestations, 2) pauci-kinetic attacks with no loss of awareness 3) pseudosyncope attacks, 4) prolonged hyperkinetic episodes accompanied by hyperventilation and auras, and 5) prolonged axial dystonic 'seizures' [48]. PNES semiology mimics that of epileptic seizures in patients with dual diagnosis in about one third of cases $[6,8]$.

Complex movements involving writhing, flailing and body thrashing are more common in PNES, and usually last more than $3 \mathrm{~min}[49,50]$. Opisthotonic posturing is more likely in PNES and hardly represent an epileptic seizure [51]. Five controlled and three uncontrolled studies have shown that ictal eye closure during an attack is a prominent feature in PNES [50, 52-58].

Shaking movements are usually tremulous in PNES and do not involve a rapid muscle contraction followed by a slower movement associated with muscle relaxation, which characteristically occurs in tonic-clonic seizures. These convulsive movements gradually slow down in tonic-clonic epileptic seizures while their amplitude increases [59]. In PNES the frequency of the convulsive movements does not tend to change while the amplitude varies and movements often stop abruptly [60].

PNES are more commonly associated with moaning or weeping than epileptic seizures [61]. Ictal speech, if present in PNES, is usually emotional while speech. In contrast, speech featuring in epileptic seizures tends to be monotone with the repetition of phrases or sounds and without any meaning [62]. Also, speech in PNES is more likely to be intelligible with patients providing (partial) responses to questions [63].

In the absence of motor features, the distinction between PNES and (epileptic) focal impaired awareness or absence seizures can be difficult. Altough temporal lobe seizures may have no motor manifestation and only be associated with impairment of awareness and behavioral arrest [62], 'swooning' attacks involving limp collapse into a state the patient is still and unresponsive are more likely PNES, especially in the cases they last more than $60 \mathrm{~s}$ [60].

Diagnosticians need to be aware of the typical semiology of frontal lobe seizures which can involve elements also seen in PNES such as partial awareness and responsiveness during seizures, flailing, thrashing [51], side-toside movements of the head or turning of the body [62]. The longer duration of most PNES ( $>2 \mathrm{~min}$ ) may help to distinguish PNES from frontal lobe seizures [57, 62, 6468]. It may also help that frontal lobe seizures often occur from sleep $[62,64,69]$ while PNES from actual sleep are an exceptionally rare phenomenon [70].

Mistakes are also commonly made in the differentiation of epileptic seizures of parietal origin and PNES. The wide range of semiological features, with sensory auras and heterogenous motor semiology of dystonic and hyperkinetic movements, may lead to diagnostic errors especially when ictal EEG discharges are not evident in scalp EEG recordings [71].

In their assessment of the seizure semiology, clinicians will need to be aware that no single feature should be relied upon for the differential diagnosis which instead needs to take account of the full semiological context and all other clinical information available on the patients. Diagnosticians also need to consider what the source of the semiological data is which they are using for their decision-making process. For instance, persistent eye closure is very frequently observed in PNES captured with video-EEG [55], but it is often misreported by witnesses [58]. This sign is therefore only a reliable diagnostic pointer in the presence of video documentation of seizures. Other features historically relied upon to help with the differential diagnosis between PNES and epilepsy, which are not reliable in isolation and in the absence of direct observation or recording of a seizure include urinary incontinence $[1,72]$, injury $[1,73]$, tongue biting $[1,72,73]$, provocation by flashing lights $[74,75]$, autonomic manifestations $[61,76,77]$ and nocturnal attacks [13, 78-80]]. Similarly, while PNES are usually longer than epileptic seizures $[67,68]$, information from seizure witnesses about the duration of seizures is too unreliable to be diagnostically useful. Although careful video-EEG analysis usually reveals that epileptic seizures are more 
stereotyped than PNES in most patients, research has shown that, once established, PNES are become rather stereotyped as well [81]. Patients with PNES and their caregivers may report seizures from sleep, raising the clinical suspicion of epileptic seizures. However, videoEEG recordings typically reveal that such PNES arise from 'pseudosleep' [82-84], i.e. the patient seems to be asleep but the EEG demonstrated that they are in fact awake at the moment of PNES onset [79].

\section{Diagnostic process}

The diagnosis of PNES is mainly clinical and often difficult, especially in those with pre- or coexisting epilepsy, where it presents an ongoing challenge when seizures persist after the initial diagnostic characterization [85]. PNES almost always follow the development of epilepsy [18], and physicians should be alert to the possibility of PNES when seizures change in frequency and/or severity or when unusual seizure patterns occur (for instance the absence of seizures during summer vacation) [71]. The diagnosis of PNES is based on the combination of data derived from various sources e.g. history, witnesses' descriptions and investigations.

\section{History taking}

The diagnostic process usually begins with the patient's history. No single seizure feature in the history has high diagnostic value. Seizure manifestation profiles may help to distinguish epileptic seizures from PNES [12], especially when information from patients themselves is combined with observations made by witnesses [86].

It is of great diagnostic help, not only to note what seizure symptoms patients mention but how they describe their seizures. Several conversation analytic studies from Germany, the United Kingdom, Italy, France and China have demonstrated that patients with epilepsy describe their subjective symptoms and try to communicate in details what their seizures feel like, while patients with PNES prefer to talk about the situations in which they had their seizures or what consequences the seizures had [87-91]. However, although clinical experience suggests that conversation analytic observations can be helpful in patients with a dual diagnosis of PNES and epilepsy, the conversational profiles of patients with such more complex seizure disorders have not been described so far.

\section{Home video recordings}

The initial diagnosis (and ongoing diagnostic confirmation) has been greatly facilitated by the increasing availability of home video recordings of seizures) [50]. In conjunction with clear clinical data, video alone can allow a reasonably confident diagnosis in many cases, and is most accurate in seizures where there is motor activity
[50, 92, 93]. The limitations of home video recordings include that videos often miss the seizure onset, may not capture parts of the patients' body and certainly miss the information added by EEG recording.

\section{Direct seizure observation}

Occasionally the diagnosis can be made by direct seizure observation. Examination findings suggestive of PNES include persistent closure of the eyes with resistance to opening, unexpected responsiveness to environmental stimuli [71], such as verbal and tactile stimuli (the use of painful stimuli is discouraged) $[1,85,94,95]$, a normal pupillary light response and absence of cyanosis [71]. In addition, testing for avoidance, such as resistance to eye opening or a controlled fall of the hand when it is dropped over the patient's face, may demonstrate muscle tone and self-protective movements in apparently atonic or dialeptic attacks that would not be expected to be observed in patients with epilepsy and loss of awareness $[1,85,94]$.

However, even if they witnessed a seizure, neurologists may assign an incorrect diagnosis in up to $25 \%$ of cases $[81,96]$.

\section{Scalp EEG recordings}

As a general principle, only ictal EEG can be used to differentiate PNES from epileptic seizures in patients with dual diagnoses, since many of these patients will have interictal findings typical of epilepsy. This means that routine EEG records which fail to capture seizures are of no particular diagnostic use in patients with dual diagnoses. Ambulatory EEG recordings without video also have significant limitations as they do not capture pre-, peri- and post-ictal behavior [97]. The EEG seizure onset may also not be captured because of the relatively low electrode density and, in the absence of video, rhythmic changes on the EEG may be more likely to be misinterpreted as epileptiform when they are artefactual in nature. Even when separate video-recordings are used, they are typically not time-locked to the EEG.

When only ictal EEG (and no video) is available for analysis, particular attention should be paid to the preictal and post-ictal EEG findings [60]. During the convulsive part of a seizure the EEG is often obscured by muscle artifacts, but the EEG activity just prior to seizure onset (for instance by demonstrating wakefulness in someone reporting seizures from apparent sleep) or the absence of immediately postictal changes in the EEG after the end of a bilateral tonic-clonic seizure may be suggestive of PNES [71].

Patients' subjective seizure experiences need to be taken into account when EEG data are interpreted, especially in the absence of time-locked video data. For 
instance, some seizures could not be expected to be associated with ictal EEG changes: only $10-30 \%$ of focal aware seizures are found to be associated with definite EEG correlates in scalp recordings [98].

Ideally patients would undergo ictal testing during any (video-) EEG examination so their ictal responsiveness would be documented and they could be asked to demonstrate potential of recall of the ictal testing later. Ictal awareness may be examined by simple verbal commands (eg. 'stick out your tongue') [99]. Even if the patients are unable to respond or follow the command, they should be given a word (e.g. a number) to remember and asked later whether they recall this word and/or any other aspects of the attack. Patients with apparent loss of awareness have previously been reported to be more responsive to external stimuli during PNES and may have more detailed recall of the ictal examination [100-102]. Testing ictal awareness is the most important assessment because the presence of symmetrical alpha activity during an attack with documented loss of awareness is very strongly suggestive of a PNES [94].

\section{Peri-ictal Ictal ECG changes}

An ECG recording time-locked to any EEG recordings can also provide diagnostic pointers. Epileptic seizures are typically associated with a more sudden heart rate (HR) increase PNES [77, 103-105]. If there are marked ictal motor manifestations, the peak HR is higher in epileptic seizures than PNES [105], with bilateral tonicclonic seizures provoking the highest HR [105]. When the ictal HR increases by more than $30 \%$ over the baseline HR, the positive predictive value for an epileptic seizure is as high as 97\% [77], although the peak ictal HR does not differentiate well between PNES and frontal epileptic seizures. The more rapid postictal HR reduction in frontal epileptic seizures and the more gradual pre-ictal HR increase in PNES can be diagnostic value in the context of frontal lobe epilepsy [103].

\section{Video-EEG}

The simultaneous video-EEG (vEEG) recording of typical seizures, in combination with the history of patients and witnesses, offers a diagnostic 'gold-standard' with high levels of certainty and excellent inter-rater reliability for PNES [106-108]. It is particularly important in patients with mixed seizure disorders.

Most patients with PNES admitted for video EEG are likely to have an attack during the first few hours of video EEG recording [109]. However, the recording should not be discontinued in patients with different types of seizures after the first event is captured, since a PNES may occur first in a patient with a mixed (epileptic and nonepileptic) seizure disorder and epileptic seizures may be observed later during the recording period, perhaps when antiseizure medications have been weaned off [110].

In view of the importance of video-EEG documentation of the diagnosis for subsequent treatment, multiple attempts to capture seizures by video-EEG may be required.

\section{Provocation techniques}

In order to increase the yield of video-EEG recordings and shorten the duration of monitoring, provocation/ suggestion techniques are sometimes used. These techniques have been endorsed by the PNES Task Force of the International League Against Epilepsy, when no episode is captured during routine recording [85]. However, particular care needs to be taken to ensure that any provoked seizures are actually typical of the patient's habitual events and that all the seizure types described by a patient have been captured (or at least characterized as well as possible) when the diagnosis is formulated [95].

Any measure that directs the patients' attention to their seizures can act as a provocation technique. Seizure provocation could simply taking a detailed history of the attack, reading out seizure descriptions from the notes and clarifying details [95]. Stating that routine activation techniques, such photic stimulation and hyperventilation, occasionally elicit a seizure may have a more suggestive force [111]. Of the different nocebo techniques to provoke seizures in suspected PNES patients, the injection of intravenous saline has been most widely used. Although there are studies suggesting the use of these interventions, these they are subject to ongoing ethical debate. They also come with a risk of patients to have atypical attacks of no diagnostic value. Especially in patients with epilepsy and PNES, these techniques may lead to diagnostic errors, since they provide little direct information about the relative frequency of the different seizure types. [112]. Although many centers use suggestion/provocation techniques, these techniques have less important role in patients with mixed epileptic seizures and PNES diagnosis as they provide little direct information about the relative frequency of the different seizure types.

\section{Showing seizure videos to patients and witnesses}

It is important to obtain detailed descriptions of the subjective and objective manifestations of all seizure types the patient has experienced prior to the application of EEG electrodes [113]. The patient's account of their seizures should be complemented by that of a seizures' witness whenever possible [114]. The presence of an eyewitness of seizures during the EEG recordings should not be discouraged. Some patients with PNES have attacks more often, or only, in the presence of others 
$[115,116]$. If witnesses could not observe the seizure during the recording procedure, they should be shown the video later to confirm that the recorded episodes were the patient's habitual attacks $[117,118]$. This would be particularly important if the patient has a mixed seizure disorder and patients and witnesses need to learn to distinguish between epileptic seizures and PNES $[95,119]$.

\section{Neuropsychiatric assessment}

It is known that patients with PNES have high rates of psychiatric illness [120], irrespective of the presence of co-morbid/pre-existing epilepsy. At least one current ('comorbid') psychiatric disorder can be identified in almost all patients with PNES [2, 121]. Most patients fulfill the diagnostic criteria of a dissociative disorder in the ICD-10 [122] or of a functional neurological symptom disorder in the DSM-5 $[60,123]$. Depression, anxiety, post-traumatic stress disorder, personality disorder, psychosis and intermittent explosive disorder are also more frequent than in the general population $[4,25,124-126]$.

Several studies suggest that, in terms of psychopathology and adverse life experiences, patients with PNES and epilepsy resemble those with PNES alone more than those with epilepsy [126]. For example, somatization is more common in patients with pure PNES or a dual diagnosis than those with epilepsy alone [124, 125], while comorbid mood disorders are the commonest psychiatric pathology in those with epilepsy [124]. Furthermore, Galimberti et al. found a higher prevalence of cluster B personality disorders in patients with mixed seizures or those with PNES than in their group of patients with epilepsy alone [124].

While the heterogeneous profile of psychiatric disorders associated with PNES is not sufficiently unique to allow a clear diagnostic distinction between patients with epilepsy only and those with mixed seizure disorders, a neuropsychiatric assessment can help to characterise patients diagnosis more comprehensively and to guide treatment - including the modification of ASMs, the use of psychotherapy or psychotropic medications $[25,124$, 126].

\section{Biomarkers}

Laboratory tests have limited role in the diagnosis of PNES and are even more limited in the diagnostic characterization of patients with mixed seizure disorders. Capillary oxygen saturation, measured on pulse oximetry during episodes tends to be higher in patients with PNES than in patients suffering from tonic-clonic epileptic seizures [127].
Postictal creatine phosphokinase (CPK) levels are usually elevated after tonic-clonic seizures [128, 129] and not after convulsive PNES [129].

Serum prolactin (PRL) is increased in most patients 10-20 min after a tonic-clonic epileptic seizure [130, 131], remaining elevated for up to $2 \mathrm{~h}$ thereafter [45]. As such postictal PRL can make be a useful diagnostic pointer after tonic-clonic-like seizures [129, 131-134], but is less useful in other types of seizures [135]. PRL levels should never be used alone for an epilepsy diagnosis, since false positive and negative results may occur [136].

\section{Ongoing need to distinguishing between epileptic seizures and PNES}

When a mixed seizure disorder has been diagnosed, the physician should try to explain both diagnoses to patients and care givers and educate them about the differences between these two types of seizures. It is advisable to check whether patients and families have learned to distinguish successfully between the two different seizure types by encouraging families to video attacks and trying to identify the attack type. Furthermore, patients and caregivers need to learn how to deal with seizure emergencies acutely. In cases in which epileptic seizure require the administration of rescue medications (e.g. midazolam) by care givers this would be particularly important, as benzodiazepines may aggravate nonepileptic / dissociative seizure states. Instead, in episodes of PNES, patients should be offered verbal reassurance, and their risk of injury should be minimized. Ambulance call outs or other interventions that could exacerbate anxiety should be avoided [71].

\section{Conclusion}

Although at least $80 \%$ of patients with seizures only have epileptic or nonepileptic seizures, a substantial minority of patients have seizure disorders in which epilepsy and PNES coexist. In such patients with a dual diagnoses clinicians face significant challenges, not only with the initial diagnosis but also once treatment has been suggested and when patients are followed up.

Patients with mixed seizure disorders may become frequent users of emergency services or end up with multiple admissions to epilepsy monitoring units. If PNES are not recognized, there is a high risk of misinterpreting epilepsy as refractory, leading to inappropriate polypharmacy, ASM toxicity and needless surgical procedures such as vagus nerve stimulator implantation, or even epilepsy surgery $[47,137]$. Clinicians always need to be wary of accepting a diagnostic label of 'known epilepsy' without (at least brief) critical examination. 
Neurologists need to be more aware of the interactions of epilepsy and mental health. The assessment of their patient should not be limited to questions about seizure symptoms, seizure frequency and side effects. Clinicians should aim to develop a holistic understanding of their patients, explore their current and previous life circumstances (especially in terms of trauma or neglect) and be interested in the context in which seizures occur. During the diagnostic process, patients should feel like partners in a search for the diagnosis rather than the subjects of the doctors' actions and decisions.

This narrative review has summarized some of the clinical features and investigations which can help clinicians to identify patients with epilepsy and PNES and to formulate optimal management plans.

\section{Abbreviations}

PNES: Psychogenic non-epileptic seizures; EEG: Electroencephalographic; ASM: Antiseizure medicine; ID: Intellectual disability; ICM: Integrative Cognitive Model; PTSD: Post-traumatic stress disorder; IQ: Intelligence Quotient; MRI: Magnetic resonance imaging; HR: Heart rate; ICD-10: International Classification of Diseases-10; CPK: Creatine phosphokinase; PRL: Serum prolactin.

\section{Acknowledgements}

Not applicable.

\section{Authors' contributions}

Dr. Andreas Liampas is the first author of this manuscript. Dr. Sofia Markoula conceived the idea of this paper and helped with its writing and revision. Dr. Panagiotis Zis also helped with the revision and the form of the paper. Dr. Markus Reuber supervised the whole project and helped to write and revise the manuscript. All authors read and approved the final manuscript.

\section{Funding}

No funding was achieved.

\section{Availability of data and materials}

Not applicable.

\section{Declarations}

\section{Ethics approval and consent to participate}

This article is based on previously conducted studies and does not contain any studies with human participants performed by any of the authors. Therefore, ethics review was not required.

\section{Consent for publication}

All authors consented to publish this study.

\section{Competing interests}

The authors declare no conflicts of interest.

\section{Author details}

${ }^{1}$ Department of Neurology, Nicosia New General Hospital, Nicosia, Cyprus. ${ }^{2}$ Department of Neurology, University Hospital of loannina, loannina, Greece. ${ }^{3}$ Medical School, University of Cyprus, Nicosia, Cyprus. ${ }^{4}$ Academic Neurology Unit, Royal Hallamshire Hospital, University of Sheffield, Sheffield, UK.

Received: 25 May 2021 Accepted: 23 August 2021

Published online: 28 September 2021

\section{References}

1. Reuber M, Elger CE. Psychogenic nonepileptic seizures: review and update. Epilepsy Behav. 2003;4(3):205-16.

2. D’Alessio L, Giagante B, Oddo S, Silva WW, Solís P, Consalvo D, et al. Psychiatric disorders in patients with psychogenic non-epileptic seizures, with and without comorbid epilepsy. Seizure. 2006;15:333-9.

3. Duncan R, Razvi S, Mulhern S. Newly presenting psychogenic nonepileptic seizures: Incidence, population characteristics, and early outcome from a prospective audit of a first seizure clinic. Epilespy Behav. 2011;20:308-11.

4. Kutlubaev MA, Xu Y, Hackett ML, Stone J. Dual diagnosis of epilepsy and psychogenic nonepileptic seizures: Systematic review and meta-analysis of frequency, correlates, and outcomes. Epilepsy Behav. 2018;89:70-8.

5. Yon Ml, Azman F, Tezer Fl, Saygi S. The coexistence of psychogenic nonepileptic and epileptic seizures in the same patient is more frequent than expected: Is there any clinical feature for defining these patients? Epilepsy Behav. 2020;105:106940.

6. Devinsky O, Sanchez-Villasenor F, Vazquez B, Kothari M, Alper K, Luciano D. Clinical profile of patients with epileptic and nonepileptic seizures. Neurology. 1996;46:1530-3.

7. Krumholz A. Nonepileptic seizures: diagnosis and management. Neurology. 1999;53(5 Suppl 2):S76-83.

8. Reuber M, Qurishi A, Bauer J, Helmstaedter C, Fernandez G, Widman $\mathrm{G}$, et al. Are there physical risk factors for psychogenic non-epileptic seizures in patients with epilepsy? Seizure. 2003;12:561-7.

9. Cuthill FM, Espie CA. Sensitivity and specificity of procedures for the differential diagnosis of epileptic and non-epileptic seizures: a systematic review. Seizure. 2005:14(5):293-303.

10. Hantke NC, Doherty MJ, Haltiner AM. Medication use profiles in patients with psychogenic nonepileptic seizures. Epilepsy Behav. 2007;10(2):333-5.

11. Reuber M, Baker GA, Gill R, Smith DF, Chadwick DW. Failure to recognize psychogenic nonepileptic seizures may cause death. Neurology. 2004;62(5):834-5

12. Reuber M, Fernandez G, Bauer J, Helmstaedter C, Elger CE. Diagnostic delay in psychogenic nonepileptic seizures. Neurology. 2002;58:493-5.

13. Asadi-Pooya AA, Emami M. Demographic and clinical manifestations of psychogenic non-epileptic seizures: the impact of co-existing epilepsy in patients or their family members. Epilepsy Behav. 2013;27(1):1-3.

14. Glosser G, Roberts D, Glosser DS. Nonepileptic seizures after resective epilepsy surgery. Epilepsia. 1999;40(12):1750-4

15. Henry TR, Drury I. Non-epileptic seizures in temporal lobectomy candidates with medically refractory seizures. Neurology. 1997;48(5):1374-82.

16. Rosenbaum M. Psychogenic seizures-why women? Psychosomatics. 2000:41:147-9.

17. Chodoff P. Hysteria and women. Am J Psychiatry. 1982;139:545-51.

18. Baroni G, Piccinini V, Martins WA, de Paola L, Paglioli E, Margis R, et al. Variables associated with co-existing epileptic and psychogenic nonepileptic seizures: a systematic review. Seizure. 2016;37:35-40.

19. Duncan R, Oto M. Psychogenic nonepileptic seizures in patients with learning disability: comparison with patients with no learning disability. Epilepsy Behav. 2008;12(1):183-6.

20. Vincentiis S, Valente KD, Thome-Souza S, Kuczinsky E, Fiore LA, Negrao N. Risk factors for psychogenic nonepileptic seizures in children and adolescents with epilepsy. Epilepsy Behav. 2006;8(1):294-8.

21. Kellinghaus C, Loddenkemper T, Dinner DS, Lachhwani D, Luders HO. Non-epileptic seizures of the elderly. J Neurol. 2004;251(6):704-9.

22. Goldstein LH, Robinson EJ, Reuber M, Chalder T, Callaghan H, Eastwood C, et al. Characteristics of 698 patients with dissociative seizures: A UK multicenter study. Epilepsia. 2019;60(11):2182-93.

23. Nightscales R, McCartney L, Auvrez C, Tao G, Barnard S, Malpas CB, et al. Mortality in patients with psychogenic nonepileptic seizures. Neurology. 2020;95(6):e643-52.

24. Reuber M, Howlett S, Khan A, Grunewald RA. Non-epileptic seizures and other functional neurological symptoms: predisposing, precipitating, and perpetuating factors. Psychosomatics. 2007;48(3):230-8.

25. Kuyk J, Swinkels WA, Spinhoven P. Psychopathologies in patients with nonepileptic seizures with and without comorbid epilepsy: how different are they? Epilepsy Behav. 2003;4:13-8. 
26. Devinsky O, Gordon E. Epileptic seizures progressing into nonepileptic conversion seizures. Neurology. 1998;51(5):1293-6.

27. Lelliott PT, Fenwick P. Cerebral pathology in pseudoseizures. Acta Neurol Scand. 1991;83(2):129-32.

28. Fiszman A, Alves-Leon SV, Nunes RG, D'Andrea I, Figuera I. Traumatic events and posttraumatic stress disorder in patients with psychogenic nonepileptic seizures: a critical review. Epilepsy Behav. 2004;5:818-25.

29. Duncan R, Oto M. Predictors of Antecedent Factors in Psychogenic Nonepileptic Attacks: Multivariate Analysis. Neurology. 2008;71(13):1000-5.

30. Hesdorffer DC, Ishihara L, Mynepalli L, Webb DJ, WeilJ, Hauser WA. Epilepsy, suicidality, and psychiatric disorders: a bidirectional association. Ann Neurol. 2012;72(2),184-91. https://doi.org/10.1002/ana.23601

31. Kanner AM. The treatment of depressive disorders in epilepsy: what all neurologists should know. Epilepsia. 2013;54(Suppl 1):3-12.

32. Piedad J, Rickards H, Besag FM, Cavanna AE. Beneficial and adverse psychotropic effects of antiepileptic drugs in patients with epilepsy: a summary of prevalence, underlying mechanisms and data limitations. CNS Drugs. 2012;26(4):319-35.

33. Puka K, Tavares TP, Speechley KN. Social outcomes for adults with a history of childhood-onset epilepsy: a systematic review and metaanalysis. Epilepsy Behav. 2019;92:297-305.

34. Yildirim Z, Ertem DH, Dirican AC, Baybas S. Stigma accounts for depression in patients with epilepsy. Epilepsy Behav. 2018;78:1-6.

35. Yildirim Z, Ertem DH, Ceyhan Dirican A, Baybas S. Who is the bigger stigmatizor?: the loved one or the society. Epilepsy Behav. 2019;96:13-22.

36. Niedermeyer E, Blumer D, Holscher E, Walker BA. Classical hysterical seizures facilitated by anticonvulsant toxicity. PsychiatrClin (Basel). 1970;3(2):71-84

37. Devinsky O, Mesad S, Alper K. Nondominant hemisphere lesions and conversion nonepileptic seizures. J Neuropsychiatry ClinNeurosci. 2001;13:367-73.

38. Ferguson SM, Rayport M. The Adjustment to Living without Epilepsy. J Nerv Ment Dis. 1965;140:26-37.

39. Krahn LE, Rummans TA, Sharbrough FW, Jowsey SG, Cascino GD. Pseudoseizures after epilepsy surgery. Psychosomatics. 1995;36(5):487-93.

40. Ney GC, Barr WB, Napolitano C, Decker R, Schaul N. New-onset psychogenic seizures after surgery for epilepsy. Arch Neurol. 1998;55(5):726-30.

41. Parra J, Iriarte J, Kanner AM, Bergen DC. De novo psychogenic nonepileptic seizures after epilepsy surgery. Epilepsia. 1998;39(5):474-7.

42. Montenegro MA, Guerreiro MM, Scotoni AE, Stella F, Leone AA, Honorato $D C$, et al. De novo psychogenic seizures after epilepsy surgery: case report. Arq Neuropsiquiatr. 2000;58(2B):535-7.

43. Reuber, M, Kral T, Kurthen M, Elger CE. New-Onset Psychogenic Seizures after Intracranial Neurosurg. 2002;144(9):901-7.

44. Markoula S, de Tisi J, FoongJ, Duncan JS. De novo psychogenic nonepileptic attacks after adult epilepsy surgery: An underestimated entity. Epilepsia. 2013;54(12):e159-e162

45. Sundararajan T, Tesar GE, Jimenez XF. Biomarkers in the diagnosis and study of psychogenic nonepileptic seizures: A systematic review. Seizure. 2016:35:11-22.

46. Wilson S, Bladin P, Saling M. The, "burden of normality": concepts of adjustment after surgery for seizures. J Neurol Neurosurg Psychiatry. 2001;70(5):649-56.

47. Gonzalez Otarula KA, Tan YL, Dubeau F Correa JA, Chang E, Hall JA et al. Psychogenic nonepileptic seizures in patients with surgically treated temporal lobe epilepsy: Presurgical and de novo postsurgical occurrence. Epilepsy Behav. 2017;75:252-255.

48. Hubsch C, Baumann C, Hingray C, Gospodaru N, Vignal JP, Vespignani H, et al. Clinical classification of psychogenic non-epileptic seizures based on video-EEG analysis and automatic clustering. J Neurol Neurosurg Psychiatry. 2011;82(9):955-60.

49. Devinsky O, Gazzola D, LaFrance WC Jr. Differentiating between nonepileptic and epileptic seizures. Nat Rev Neurol. 2011;7(4):210-20.

50. Chen DK, Graber KD, Anderson CT, Fisher RS. Sensitivity and specificity of video alone versus electroencephalography alone for the diagnosis of partial seizures. Epilepsy Behav. 2008;13:115e8.
51. Avbersek A, Sisodiya S. Does the primary literature provide support for clinical signs used to distinguish psychogenic nonepileptic seizures from epileptic seizures? J Neurol Neurosurg Psychiatry. 2010;81:719-25.

52. Gulick TA, Spinks IP. King DW. Pseudoseizures: ictal phenomena. Neurology. 1982;32:24-30.

53. Flügel D, Bauer J, Käseborn U, Burr W, Elger CE. Closed eyes during a seizure indicate psychogenic etiology: a study with suggestive seizure provocation. J Epilepsy. 1996;9:165-9.

54. DeToledo JC, Ramsay RE. Patterns of involvement of facial muscles during epileptic and nonepileptic events: review of 654 events. Neurology.1996;47:621e5.

55. Chung SS, Gerber P, Kirlin KA. Ictal eye closure is a reliable indicator for psychogenic nonepileptic seizures. Neurology. 2006:66:1730e1.

56. Hovorka J, Nezádal T, Herman E, Nemcová I, BajacekM. Psychogenic non-epileptic seizures, prospective clinical experience: diagnosis, clinical features, risk factors, psychiatric comorbidity, treatment outcome. Epileptic Disord. 2007;9Suppl 1:S52-8.

57. Azar NJ, Tayah TF, Wang L, Song Y, Abou-Khalil BW. Postictal breathing pattern distinguishes epileptic from nonepileptic convulsive seizures. Epilepsia. 2008:49:132-7.

58. Syed TU, Arozullah AM, Suciu GP, Toub J, Kim H, Dougherty ML, et al. Do observer and self-reports of ictal eye closure predict psychogenic nonepileptic seizures? Epilepsia. 2008;49(5):898-904.

59. Vinton A, Carino J, Vogrin S, Macgregor L, Kilpatrick C, Matkovic Z, et al. "Convulsive" nonepileptic seizures have a characteristic pattern of rhythmic artifact distinguishing them from convulsive epileptic seizures. Epilepsia. 2004;45:1344-50.

60. Oto M, Reuber M. Psychogenic non-epileptic seizures: Aetiology, diagnosis and management. Adv Psychiatric Treat. 2014;20:13-22.

61. Goldstein LH, Mellers JD. Ictal symptoms of anxiety, avoidance behaviour, and dissociation in patients with dissociative seizures. J Neurol Neurosurg Psychiatry. 2006;77:616-21.

62. Saygi S, Katz A, Marks DA, Spencer SS. Frontal lobe partial seizures and psychogenic seizures: comparison of clinical and ictal characteristics. Neurology. 1992;42:1274-7.

63. Bodde NM, Brooks JL, Baker GA, Boon PA, Hendriksen JG, Aldenkamp AP. Psychogenic non-epileptic seizures-diagnostic issues: a critical review. Clin Neurol Neurosurg. 2009;111:1-9.

64. Pierelli F, Chatrian GE, Erdly WW, Swanson PD. Long-term EEGvideo-audio monitoring: detection of partial epileptic seizures and psychogenic episodes by 24-hour EEG record review. Epilepsia. 1989:30:513e23.

65. Brown MC, Levin BE, Ramsay RE, Katz DA, Duchowny MS. Characteristics of patients with nonepileptic seizures. J Epilepsy. 1991;4:225e9.

66. Henry TR \& Drury I. Ictal behaviors during nonepileptic seizures differ in patients with temporal lobe interictalepileptiform EEG activity and patients without interictalepileptiform EEG abnormalities. Epilepsia. 1998;39:175e82.

67. Jedrzejczak J, Owczarek K, Majkowski J. Psychogenic pseudoepileptic seizures: clinical and electroencephalogram (EEG) video-tape recordings. Eur J Neurol. 1999;6:473e9.

68. Selwa LM, Geyer J, Nikakhtar N, Brown MB, Schuh LA, Drury I. Nonepileptic seizure outcome varies by type of spell and duration of illness. Epilepsia. 2000;41:1330-4.

69. Bazil CW \&Walczak TS. Effects of sleep and sleep stage on epileptic and nonepileptic seizures. Epilepsia. 1997;38:56e62.

70. Orbach D, Ritaccio A, Devinsky O. Psychogenic nonepileptic seizures associated with video-EEG confirmed sleep. Epilepsia. 2003;44:64-8.

71. Markoula S \& Reuber M. Epilepsy and psychogenic nonepileptic seizures. Chapter 18-The Comorbidities of Epilepsy. 2019:343-366.

72. Brigo F, Nardone R, Ausserer H, Storti M, Tezzon F, Manganotti P et al. The diagnostic value of urinary incontinence in the differential diagnosis of seizures. Seizure: J Br Epilepsy Assoc. 2013; 22:85-90.

73. Asadi-Pooya AA, Emami Y, Emami M. Psychogenic non-epileptic seizures in Iran. Seizure. 2014;23(3):175-7.

74. Meierkord H, Will B, Fish D, Shorvon S. The clinical features and prognosis of pseudoseizures diagnosed using video-EEG telemetry. Neurology. 1991:41:1643-6.

75. Goyal G, Kalita J, Misra UK. Utility of different seizure induction protocols in psychogenic nonepileptic seizures. Epilepsy Res. 2014;108:1120-7. 
76. Smith PEM Howell SJ Owen L, Blumhardt LD. Profiles of instant heart rate during partial seizures. Electroencephal Clin Neurophysiol. 1989:72(3):207-17.

77. Opherk C, Hirsch LJ. Ictal heart rate differentiates epileptic from nonepileptic seizures. Neurology. 2002;58:636-8.

78. Thacker K, Devinsky O, Perrine K, Alper K, Luciano D. Nonepileptic seizures during apparent sleep. Ann Neurol. 1993;33:414-8.

79. Benbadis SR, Lancman ME, King LM, Swanson SJ. Preictalpseudosleep: a new finding in psychogenic seizures. Neurology. 1996:47:63-7.

80. Duncan R, Oto M, Russell AJ, Conway P. Pseudosleep events in patients with psychogenic non-epileptic seizures: prevalence and associations. J Neurol Neurosurg Psychiatry. 2004;75:1009-12.

81. Seneviratne U, Reutens D, D'Souza W. Stereotypy of psychogenic nonepileptic seizures: insights from video-EEG monitoring. Epilepsia. 2010;51(7):1159-68.

82. Layhourne PC, Larr C. Psychogenic unconsciousness in children. J Kansas Med Soc 1968:69:114-7.

83. Hopkins A. Pretending to be unconscious. Lancet. 1973;2(312-3):14.

84. Porter J. Psychogenic unresponsiveness Iletterl. Can Med Assoc J. 1974;110:755-6.

85. LaFrance WC Jr, Baker GA, Duncan R, Goldstein LH, Reuber M. Minimum requirements for the diagnosis of psychogenic nonepileptic seizures: a staged approach: a report from the International League Against Epilepsy Nonepileptic Seizures Task Force. Epilepsia. 2013;54:2005-18

86. Chen M, Jamnadas-Khoda J, Broadhurst M, Wall M, Grunewald R, Howell $\mathrm{SJL}$, et al. Value of witness observations in the differential diagnosis of transient loss of consciousness. Neurology. 2019;92(9):895-904.

87. Schwabe M, Reuber M, Schondienst M, Gulich E. Listening to people with seizures: how can linguistic analysis help in the differential diagnosis of seizure disorders? Commun Med. 2008;5:59-72.

88. Reuber M, Monzoni C, Sharrack B, Plug L. Using Conversation Analysis to distinguish between epilepsy and non-epileptic seizures: a prospective blinded multirater study. Epilepsy Behav. 2009;16(1):139-44.

89. Cornaggia CM, Di Rosa G, Polita M, Magaudda A, Perin C, Beghi M. Conversation analysis in the differentiation of psychogenic nonepileptic and epileptic seizures in pediatric and adolescent settings. Epilepsy Behav. 2016;62:231-8.

90. Yan Y, Ma W, Reuber M, Qiang L, Yan H, Xianquin Z, et al. Conversation Analysis in differential diagnosis of epileptic seizure and psychogenic nonepileptic seizure. Chinese J Neurol. 2017:50(4):266-70.

91. Biberon J, de Liege A, de Toffol B, Limousin N, El-Hage W, Florence AM et al. Differentiating PNES from epileptic seizures using conversational analysis on French patients: A prospective blinded study. Epilepsy Behav. 2020;111,107239.

92. King DW, Gallagher BB, Murvin AJ, Smith DB, Marcus DJ, Hartlage LC, Ward 3rd LC. Pseudoseizures: Diagnostic Eval. 1982;32(1):18-23.

93. Dash D, Sharma A, Yuvraj K, Renjith A, Mehta S, Vasantha PM, et al. Can home video facilitate diagnosis of epilepsy type in a developing country? Epilepsy Res. 2016;125:19-23.

94. Lesser RP. Psychogenic seizures. Neurology. 1996;46(6):1499-507.

95. Whitehead K, Kane N, Wardrope A, Kandler R, Reuber M. Proposal for best practice in the use of video-EEG when psychogenic nonepileptic seizures are a possible diagnosis. Clin Neurophysiol Pract. 2017;22(2):130-9.

96. O'Sullivan SS, Redwood RI, Hunt D, McMahon EM, O'Sullivan S. Recognition of psychogenic non-epileptic seizures: a curable neurophobia? J Neurol Neurosurg Psychiatry. 2013;84:(2):228-231.

97. Rowan AJ, Siegel M, Rosenbaum DH. Daytime Intensive Monitoring: Comparison With Prolonged Intensive and Ambulatory Monitoring. Neurology. 1987;37(3):481-4.

98. Verma A, Radtke R. EEG of partial seizures. J Clin Neurophysiol. 2006:23(4):333-9.

99. Wilkus RJ, Dodrill CB, Thompson PM. Intensive EEG monitoring and psychological studies of patients with pseudoepileptic seizures. Epilepsia. 1984;25:(1):100-107.

100. Bell WL, Park YD, Thompson EA, Radtke RA. Ictal Cognitive Assessment of Partial Seizures and Pseudoseizures. Arch Neurol. 1998:55(11):1456-9.
101. Lancman ME, Asconapé JJ, Craven WJ, Howard G, Penry JK. Predictive Value of Induction of Psychogenic Seizures by Suggestion. Ann Neurol. 1994:35(3):359-61.

102. Reuber M, Kurthen M. Consciousness in non-epileptic attack disorder. Behav Neurol. 2011;24(1):95-106.

103. Reinsberger C, Perez DL, Murphy MM, Dworetzky BA. Pre- and postictal, not ictal, heart rate distinguishes complex partial and psychogenic nonepileptic seizures. Epilepsy Behav. 2012;23(1):68-70.

104. Ponnusamy A, Marques JL, Reuber M. Comparison of heart rate variability parameters during complex partial seizures and psychogenic nonepileptic seizures. Epilepsia. 2012;53:1314-21.

105. Tatum WO, Acton EK, Langston ME, Yelvington K, Bowman C, Shih JJ, et al. Multimodality peak Ictal vital signs during video-EEG monitoring. Seizure. 2016:40:15-20.

106. LaFrance WC Jr. Psychogenic nonepileptic seizures. Curr Opin Neurol. 2008:21(2):195-201.

107. Dickinson P, Looper KJ. Psychogenic nonepileptic seizures: a current overview. Epilepsia. 2012;53:1679-89.

108. Doss RC, LaFrance WC Jr. Psychogenic non-epileptic seizures. Epileptic Disord. 2016:18(4):337-43.

109. Ettinger AB, Devinsky O, Weisbrot DM, Goyal A, Shashikumar S. Headaches and other pain symptoms among patients with psychogenic non-epileptic seizures. Seizure. 1999;8(7):424-6.

110. Chen-Block S, Abou-Khalil BW, Arain A, Haas KF, Lagrange AH, Gallagher MJ, et al. Video-EEG results and clinical characteristics in patients with psychogenic nonepileptic spells: The effect of a coexistent epilepsy. Epilepsy Behav. 2016:62:62-5.

111. Benbadis SR. Provocative techniques should be used for the diagnosis of psychogenic nonepileptic seizures. Epilepsy Behav. 2009;15:106-9.

112. Walczak TS, Williams DT, Berten W. Utility and reliability of placebo infusion in the evaluation of patients with seizures. Neurology. 1994;44(3 Pt 1):394-9.

113. Reuber M, Chen M, Jamnadas-Khoda J, Broadhurst M, Wall M, Grunewald RA, et al. Value of patient-reported symptoms in the diagnosis of transient loss of consciousness. Neurology. 2016;87:625-33.

114. Plug L, Reuber M. Making the diagnosis in patients with blackouts: it's all in the history. Pract Neurol. 2009;9:4-15.

115. Leis AA, Ross MA, Summers AK. Psychogenic seizures: ictal characteristics and diagnostic pitfalls. Neurology. 1992;42:95-9.

116. Henry TR. Non-Epileptic Seizures. 2nd ed. By John R. Gates, and A. James Rowan, Boston/Oxford: Butterworth-Heinemann, 2000. 323 pp. Epilepsy Behav. 2000;1(2):135.

117. McGonigal A, Russell AJ, Mallik AK, Oto M, Duncan R. Use of short term video EEG in the diagnosis of attack disorders. J Neurol Neurosurg Psychiatry. 2004;75(5):771-2

118. Bazil CW, Kothari M, Luciano D, Moroney J, Song S, Vasquez B et al. Provocation of nonepileptic seizures by suggestion in a general seizure population. Epilepsia. 1994;35:(4):768-770.

119. Gordon PC, ValiengoLda C, Proenca IC, Kurcgant D, Jorge CL, Castro LH, et al. Comorbid epilepsy and psychogenic non-epileptic seizures: how well do patients and caregivers distinguish between the two. Seizure. 2014;23(7):537-41.

120. Bowman ES, Markand ON. Psychodynamics and psychiatric diagnoses of pseudoseizure subjects. Am J Psychiatry. 1996;153(1):57-63.

121. Diprose W, Sundram F, Menkes DB. Psychiatric comorbidity in psychogenic nonepileptic seizures compared with epilepsy. Epilepsy Behav. 2016;56:123-30. https://doi.org/10.1016/j.yebeh.2015.12.037.

122. World Health Organization. (1992). The ICD-10 classification of mental and behavioural disorders: clinical descriptions and diagnostic guidelines. World Health Organization. https://apps.who.int/iris/handle/ $10665 / 37958$

123. American Psychiatric Association. (2013). Diagnostic and statistical manual of mental disorders (5th ed.).

124. Galimberti CA, Ratti MT, Murelli R, Marchioni E, Manni R, Tartara A Patients with psychogenic nonepileptic seizures, alone or epilepsyassociated, share a psychological profile distinct from that of epilepsy patients. J Neurol. 2003;250(3):338-46.

125. Baroni G, Martins WA, Piccinini V, da Rosa MP, de Paola L, Paglioli E. Neuropsychiatric features of the coexistence of epilepsy and psychogenic nonepileptic seizures. J Psychosom Res. 2018;111:83-8. 
126. Labudda K, Frauenheim M, Illies D, Miller I, Schrecke M, Vietmeier N, et al. Psychiatric disorders and trauma history in patients with pure PNES and patients with PNES and coexisting epilepsy. Epilepsy Behav. 2018;88:41-8

127. James MR, Marshall H, Carew-McColl M. Pulse oximetry during apparent tonic-clonic seizures. Lancet. 1991;337:394-5.

128. Libman MD, Potvin L, Coupal L, Grover SA. Seizure vs. syncope: Measuring serum creatine kinase in the emergency department. J Gen Intern Med. 1991:6:408-12

129. Javali M, Acharya P, Shah S, Mahale R, Shetty P, Rangasetty S. Role of Biomarkers in Differentiating New-onset Seizures from Psychogenic Nonepileptic Seizures. J Neuroscie Rural Pract. 2017;08(04):581-4.

130. Fisher RS, Chan DW, Bare M, Lesser RP. Capillary prolactin measurement for diagnosis of seizures. Ann Neurol. 1991;29:187-90.

131. Willert C, Spitzer C, Kusserow S, Runge U. Serum neuron-specific enolase, prolactin, and creatine kinase after epileptic and psychogenic non-epileptic seizures. Acta Neurol Scand. 2004;109:318-23.

132. Collins WC, Lanigan O, Callaghan N. Plasma prolactin concentrations following epileptic and pseudoseizures. J Neurol Neurosurg Psychiatry. 1983;46:505-8.
133. Kurlemann G, Heyen P, Menges EM, Palm DG. Serum prolactin after cerebral and psychogenic seizures in childhood and adolescence - An additional useful method for differentiating the two forms of seizure. Klin Padiatr. 1992;204:150-4.

134. Shah AK, Shein N, Fuerst D, Yangala R, Shah J, Watson C. Peripheral WBC count and serum prolactin level in various seizure types and nonepileptic events. Epilepsia. 2001;42:1472-5.

135. Shukla G, Bhatia M, Vivekanandhan S, Gupta N, Tripathi M, Srivastava A, et al. Serum prolactin levels for differentiation of nonepileptic versus true seizures: limited utility. 2004;5(4):517-21.

136. Alving J. Serum prolactin levels are elevated also after pseudo-epileptic seizures. Seizure. 1998;7:85-9.

137. Reuber M, Kral T, Kurthen M, Elger CE. New-Onset Psychogenic Seizures after Intracranial Neurosurgery. 2002;144(9):901-7.

\section{Publisher's Note}

Springer Nature remains neutral with regard to jurisdictional claims in published maps and institutional affiliations.
Ready to submit your research? Choose BMC and benefit from:

- fast, convenient online submission

- thorough peer review by experienced researchers in your field

- rapid publication on acceptance

- support for research data, including large and complex data types

- gold Open Access which fosters wider collaboration and increased citations

- maximum visibility for your research: over $100 \mathrm{M}$ website views per year

At BMC, research is always in progress.

Learn more biomedcentral.com/submissions 